\title{
Androgen-Receptor Blockade Enhances Pulsatile Luteinizing Hormone Production in Late Pubertal Males: Evidence for a Hypothalamic Site of Physiologic Androgen Feedback Action
}

\author{
JAMES R. KERRIGAN, JOHANNES D. VELDHUIS, AND ALAN D. ROGOL
}

Departments of Pediatrics [J.R.K., A.D.R.], Internal Medicine [J.D.V.], and Pharmacology [A.D.R.] and National Science Foundation Science and Technology Center for Biological Timing [A.D.R., J.D.V.J. University of

Virginia Health Sciences Center, Charlottesville, Virginia 22908

\begin{abstract}
To determine potential mechanisms by which androgens alter gonadotropin secretion and elimination in the pubertal male, we administered the potent nonsteroidal androgen receptor blocking agent, flutamide, to eight males with Tanner IV or $\mathrm{V}$ genital development. Venous blood samples were obtained every $10 \mathrm{~min}$ for 24 $h$ and assayed for $\mathrm{LH}$ by a sensitive and high-precision fluorimmunoassay. Subjects were studied before and after the administration of flutamide. Deconvolution analysis was used to assess specific pulsatile LH secretory characteristics and estimate LH production and metabolic clearance rates quantitatively. After antagonism of endogenous androgen action, mean 24-h serum LH concentrations increased significantly. An increased mean 24-h LH production rate, without evident changes in serum $\mathrm{LH}$ half-life, accounted for the increase in average serum $\mathrm{LH}$ levels. The increased daily secretion rate of $\mathrm{LH}$ was in turn due to both an augmented mass of $\mathrm{LH}$ released per secretory episode and increased frequency of secretory events. There was no demonstrable change in the maximal rate of $\mathrm{LH}$ secretion attained within each secretory event. Serum concentrations of total testosterone, free-testosterone, and $17 \beta$-estradiol all increased during blockade of androgen action. Administration of the antiandrogen had no measurable effect on the pituitary response to a single maximally effective dose of exogenous gonadotropin releasing hormone (GnRH). These results indicate that, in the late pubertal male, endogenous androgen exerts negative feedback control of gonadotropin secretion primarily at a hypothalamic site reflected by regulation of the frequency of pulsatile LH secretion. Antiandrogen had no discernible effects on exogenous GnRH-stimulated pituitary LH release or on the elimination rate of $\mathrm{LH}$, but amplified the mass of $\mathrm{LH}$ secreted in response to endogenous $\mathrm{GnRH}$. Assuming that pituitary response to exogenous GnRH reflects responsivity to endogenous releasing factor, we can infer an augmentation of the endogenous GnRH stimulus when androgen negative feedback is withdrawn. Accordingly, we suggest that endogenous androgen acting via androgen receptors negatively regulates both the amount
\end{abstract}

Received May 12, 1993; accepted September 9, 1993.

Correspondence: Alan D. Rogol M.D., Ph.D., Division of Pediatric Endocrinology, Building MR-4/Room 3037, Box 3, University of Virginia Health Sciences Center, Charlottesville, VA 22908.

Supported by Clinical Investigator Award and HD-00926 (J.R.K.), NSF Science and Technology Center for Biological Timing (A.D.R., J.D.V.), National Institutes of Health-supported Clinfo Data Reduction Systems, and a grant from the United States Public Health Service (General Clinical Research Centers) to the University of Virginia (RR-00847). and frequency of hypothalamic GnRH release in late pubertal boys. (Pediatr Res 35: 102-106, 1994)

Abbreviations

GnRH, gonadotropin-releasing hormone $L_{v}$, body distribution volume in liters

The dynamic process of normal human puberty is heralded by dramatic increases in nocturnal gonadotropin secretion (1-3). This awakening of the CNS-hypothalamic-pituitary axis then augments gonadal steroidogenic activity, manifested as increasing serum levels of sex steroid hormones. As the adolescent matures, a feedback control system develops whereby gonadal steroid hormones modulate pulsatile gonadotropin secretion. Although it appears that androgens inhibit gonadotropin release by acting at both the hypothalamus and pituitary gland $(4,5)$, evidence exists supporting a developmental process of such feedback control.

In the pubertal male, androgens may act predominantly at the hypothalamus (6-8). As full sexual maturation is achieved, studies in GnRH-deficient patients suggest that the pituitary becomes an additional site of androgen negative feedback $(5,9)$. However, other investigators $(10,11)$ have not found a pituitary effect of androgen feedback action in the intact adult male. In addition to a direct effect of androgens via their respective receptormediated pathways, the aromatized product, estrogen, also exerts modulatory control of gonadotropin secretion (12-16). Thus, the sex steroid hormones may regulate the reproductive axis at multiple sites via alternate mechanisms.

To investigate potential mechanism(s) whereby testosterone, and/or its metabolites, alter circulating gonadotropin levels in the late pubertal male, we used the techniques of frequent venous sampling, sensitive LH fluoroimmunoassay, deconvolution analysis, antiandrogen administration, and GnRH stimulation testing. Antiandrogen administration was used to introduce selective partial blockade of androgen negative feedback via the androgen receptor. The method of deconvolution analysis applied here assesses specific secretory characteristics and the simultaneously occurring process of hormone elimination (17, 18). The application of this computer-based mathematical model to hormone concentration-versus-time series also allows estimates of subject-specific hormone production rates. Using these combined strategies, we have explored the principal loci of androgen negative feedback in the late pubertal male. 


\section{MATERIALS AND METHODS}

Subjects. Eight normal, healthy late pubertal (Tanner genital stage IV or V) males participated in this study; pubertal staging was performed according to the method of Marshall and Tanner (19). Ages ranged from 13.8 to $17.2 \mathrm{y}$. The height and weight of each subject were between the 5 th and 95 th percentiles for chronologic age (based on standards from the National Center for Health Statistics). Skeletal ages were within 2 SD for chronologic age; values of body mass index [weight/height ${ }^{2}(20)$ ] were $-0.12 \pm 0.40 \mathrm{SD}$ for skeletal age. All subjects were free of medical illness, alcohol or drug abuse, recent weight changes, and endocrine dysfunction.

Protocol. The study protocol was approved by the Human Investigation Committee at the University of Virginia and was performed in the University of Virginia General Clinical Research Center. Participants were informed of the details of the investigation. Legal consent and assent were then provided by the parents and the adolescents, respectively.

All subjects were admitted on two occasions in randomized order. For the baseline (BASELINE) admission, no medications were taken before the study. For the treatment (FLUTAMIDE) admission, subjects were administered flutamide (Eulexin, Schering Corp., Kenilworth, NJ) $250 \mathrm{mg}$ orally 4 times a day for the 3 days before-and throughout-the admission. For each admission, a heparin lock was placed in a forearm vein approximately $1 \mathrm{~h}$ before venous sampling. Blood samples were obtained at 10-min intervals for $24 \mathrm{~h}$ beginning at $0800 \mathrm{~h}$. At the end of this time, GnRH $(100 \mu \mathrm{g})$ was administered intravenously; blood samples were then obtained every $10 \mathrm{~min}$ for an additional 60 min. All other serum hormone concentrations were measured in a blood sample obtained at $0800 \mathrm{~h}$. Subjects were allowed normal ambulatory activity and received meals at 0900,1200, and 1730 h; a caffeine-free snack was provided at $2100 \mathrm{~h}$. Subjects were required to be in bed with the room lights turned out from 2300 to $0600 \mathrm{~h}$. No adverse effects of flutamide were reported.

Assays. Serum LH concentrations were determined in duplicate by fluorimmunoassay (Delfia hLH Spec, Pharmacia ENI Diagnostics Inc., Columbia, MD). The limit of assay detection is $0.3 \mathrm{IU} / \mathrm{L}$ (First International Reference Preparation) with mean intra- and interassay coefficients of variation of 5.1 and $4.3 \%$, respectively. All samples obtained from a given subject were measured in a single assay run to avoid interassay variability. Serum FSH concentrations were determined by immunoradiometric assay (Nichols Laboratories, San Juan Capistrano, CA). Total and free serum testosterone and total serum estradiol were determined in single-run assays using commercial solid phase RIA (Coat-A-Count, Diagnostic Products Corporation, Los Angeles, CA). Serum concentrations of 2-hydroxyflutamide, the biologically active metabolite of flutamide, were measured by HPLC through the generous cooperation of Schering Corporation.

Deconvolution analysis. Deconvolution analysis is a mathematical technique that, when applied to hormone concentrationversus-time series, estimates subject-specific measures of hormone production and clearance $(17,18)$. Among these are: 1$)$ the number and positions in time of significant secretory episodes, 2) secretory burst half-duration (duration of the calculated secretory episode at half-maximal amplitude), 3) amplitude (maximal secretory rate in each secretory burst), and 4) hormone half-life corresponding to a disappearance rate constant. The elimination process here was described by a monoexponential model. The mass of hormone released per secretory episode is determined as the analytical area of the secretory rate-versustime curve in a given burst. No tonic (nonpulsatile) secretion was necessary to model the present experimental data. Total daily production rates were derived as the product of secretory burst frequency and the mass of hormone released per secretory event.

Potential day-night differences of serum LH concentrations were appraised using cosinor analysis as described previously (21).

Statistical analysis. Comparisons between the baseline and the flutamide-treated state were made using the paired two-tailed $t$ test. Secretory parameters were log-transformed before statistical analysis to meet criteria of normal distribution (22). Statistical significance was accepted at a $p$ value of $<0.05$. Results are reported as the mean \pm SEM.

\section{RESULTS}

Effects of antagonism of androgen action on serum concentrations of FSH and sex steroid hormones. As summarized in Table 1 , serum concentrations of total testosterone increased during blockade of androgen receptors $(25 \pm 3$ versus $34 \pm 5 \mathrm{nmol} / \mathrm{L}$, BASELINE versus FLUTAMIDE; $p=0.04$ ). Coordinate increases in serum levels of free testosterone $(96 \pm 1$ versus $129 \pm$ $9 \mathrm{pmol} / \mathrm{L} ; p=0.001)$ and $17 \beta$-estradiol $(51 \pm 6$ versus $75 \pm 13$ pmol/L; $p=0.015$ ) were observed during the androgen-receptor opposed state. Serum FSH concentrations $(2.7 \pm 0.5$ versus 3.6 $\pm 0.5 \mathrm{IU} / \mathrm{L}$ ) did not increase significantly during antiandrogen administration. Trough serum levels of 2 -hydroxyflutamide (the active metabolite of flutamide) obtained during the latter part of $\mathrm{d} 4$ of drug administration were $1315 \pm 193 \mathrm{ng} / \mathrm{mL}$. These values are within the range of reported clinically effective concentrations (23).

Effects of androgen receptor blockade on 24- $h$ mean serum $L H$ concentrations and on $\mathrm{LH}$ production and elimination rates. Representative graphs obtained by deconvolution analysis of the LH concentration-versus-time data series are illustrated in Figure 1; representative predicted (reconvolution curve) fits to the concentration-versus-time series and LH secretory rate-versus-time curves are depicted for each of two study subjects.

The effects of androgen-receptor blockade on specific pulsatile LH secretory and elimination parameters are summarized in Figure 2 . Secretory burst frequency increased during antagonism of androgen action $(14 \pm 1$ versus $16 \pm 1$ events per $24 \mathrm{~h}$, BASELINE versus FLUTAMIDE; $p=0.04$ ). Reciprocal changes in LH interburst interval ( $105 \pm 6$ versus $85 \pm 3 \mathrm{~min} ; p=0.04)$ were observed. Accompanying these changes was an increase in the mass of hormone released per secretory event $(2.8 \pm 0.3$ versus $\left.3.4 \pm 0.4 \mathrm{IU} / \mathrm{L}_{v} ; p=0.009\right)$. Due to the observed changes in secretory burst frequency and the mass of LH secretory in each release event, the overall $\mathrm{LH}$ production rate increased during androgen receptor blockade ( $39 \pm 4$ versus $58 \pm 5$ IU/ $\mathrm{L}_{\mathrm{v}} / 24 \mathrm{~h} ; p=0.0003$ ). The maximal rate of $\mathrm{LH}$ secretion attained within each secretory episode $(0.58 \pm 0.07$ versus $0.66 \pm 0.09$ $\left.\mathrm{IU} / \mathrm{L}_{\mathrm{v}} / \mathrm{min}\right)$, the secretory burst half-duration $(5.0 \pm 0.7$ versus $5.6 \pm 0.9 \mathrm{~min})$ and the estimated LH elimination half-life $(81 \pm$ 2 versus $82 \pm 2 \mathrm{~min}$ ) were invariant of treatment. Greater $\mathrm{LH}$ production per unit distribution volume in the face of unaltered metabolic clearance of the hormone resulted in higher 24-h mean serum LH concentrations $(3.1 \pm 0.3$ versus $4.7 \pm 0.2 \mathrm{IU} / \mathrm{L} ; p=$ 0.0001 ).

No significant day-night differences of serum LH concentrations were observed for either experimental condition.

Effects of antiandrogen administration on GnRH-stimulated LH secretion. As summarized in Table 2, flutamide administration had no demonstrable effect on the pituitary response to a maximal dose of exogenous GnRH. No changes in peak serum

Table 1. Effects of androgen-receptor antagonism on serum concentrations of FSH and sex steroid hormones*

\begin{tabular}{llcc}
\hline & Baseline & Flutamide & $p$ \\
\hline Serum FSH (IU/L) & $2.7 \pm 0.5$ & $3.6 \pm 0.5$ & $\mathrm{NS}$ \\
Total testosterone $(\mathrm{nmol} / \mathrm{L})$ & $25 \pm 3$ & $34 \pm 5$ & 0.04 \\
Free testosterone $(\mathrm{pmol} / \mathrm{L})$ & $96 \pm 10$ & $129 \pm 9$ & 0.001 \\
Total 17B-estradiol $(\mathrm{pmol} / \mathrm{L})$ & $51 \pm 6$ & $75 \pm 13$ & 0.015 \\
\hline
\end{tabular}

* Data are mean \pm SEM ( $n=8$ subjects). 
A

BASELINE
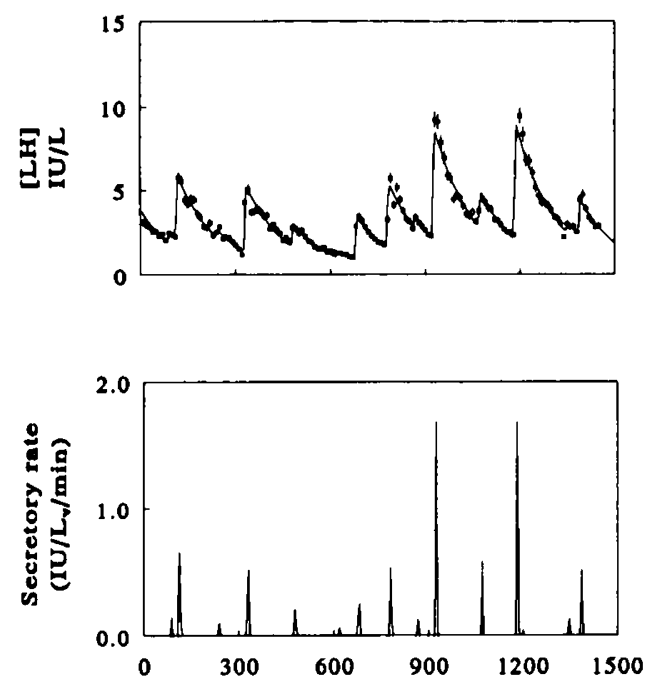

Time (min)

B

BASELINE
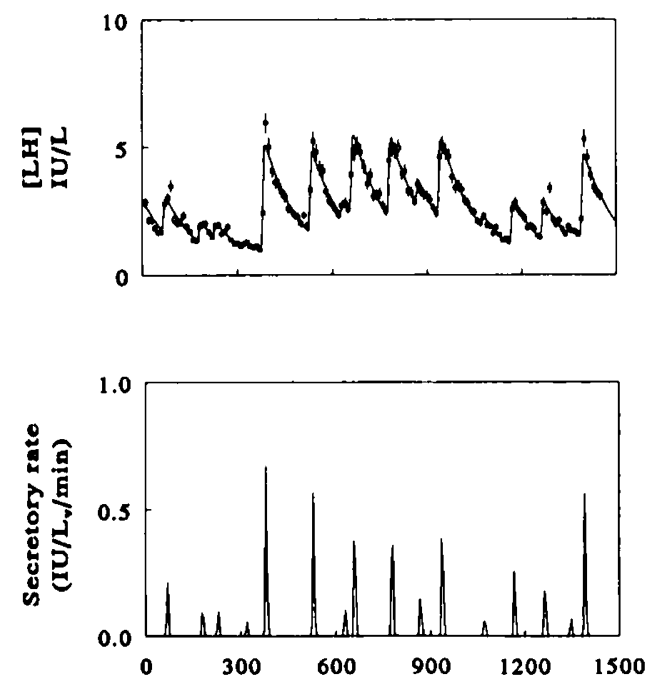

FLUTAMIDE
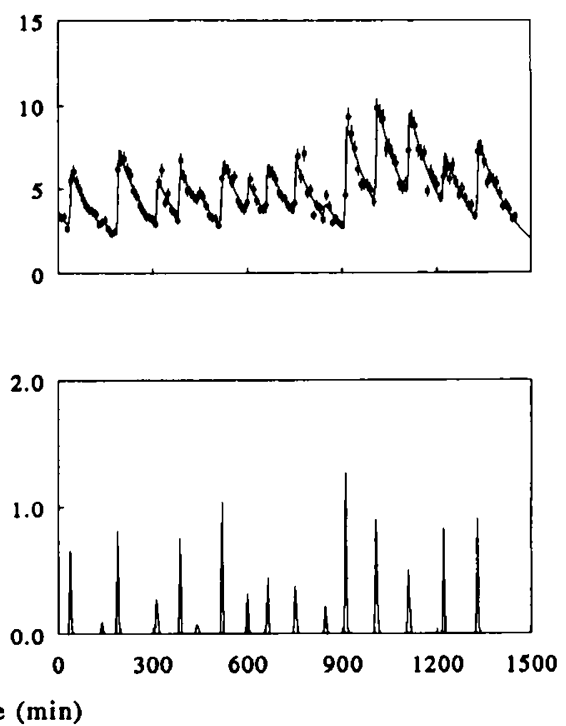

Time (min)

Fig. 1. Deconvolution analysis in two representative adolescent subjects ( $A$ and $B$ ). The upper subpanels for each subject depict the serum LH concentrations (shown as open boxes with vertical error bars representing the intrasample SDs); the continuous curves through these data represent convolution fits as predicted by deconvolution modeling. The lower subpanels for each subject present the deconvolution-resolved LH secretory rate-versus-time curves, with each peak corresponding to a discrete secretory event. Results of studies performed at baseline are shown on the left (BASELINE); those performed during flutamide treatment are on the right (FLUTAMIDE). Note the differences in vertical axis scale between the two subjects. Results for all eight subjects are summarized in Table 2.

LH concentrations ( $19 \pm 3$ versus $17 \pm 2 \mathrm{IU} / \mathrm{L}$ ) or the incremental increase in serum LH levels ( $16 \pm 2$ versus $12 \pm 2 \mathrm{IU} / \mathrm{L})$ were observed after GnRH stimulation in the androgen receptorblocked adolescent male.

\section{DISCUSSION}

Sex steroid hormones play a major role in the feedback regulation of the CNS-hypothalamic-pituitary-gonadal axis. Depending upon the species, age, and experimental conditions, androgens appear to inhibit gonadotropin secretion by acting at both the hypothalamus and pituitary gland (4). Available evidence suggests that a developmental process occurs during human male puberty such that, after hypothalamic maturation is achieved, the pituitary gland becomes an additional site of androgen negative-feedback action $(5,9)$. All of the foregoing inferences were derived from GnRH-deficient subjects treated with pulsatile GnRH or after the administration of pharmacological amounts of androgen. In intact men, LH immunoassay and bioassay both support increased endogenous GnRH release with or without an increased frequency of hypothalamic activity $(10,11)$. To our knowledge, no comparable data are available to assess androgennegative feedback in the later stages of puberty in the male. Therefore, we sought to determine potential mechanisms subserving gonadal steroid hormone modulation of gonadotropin secretion in the pubertal male. To accomplish this goal, the techniques of intensive venous sampling, sensitive, specific and precise LH fluorimmunoassay, deconvolution analysis, and 

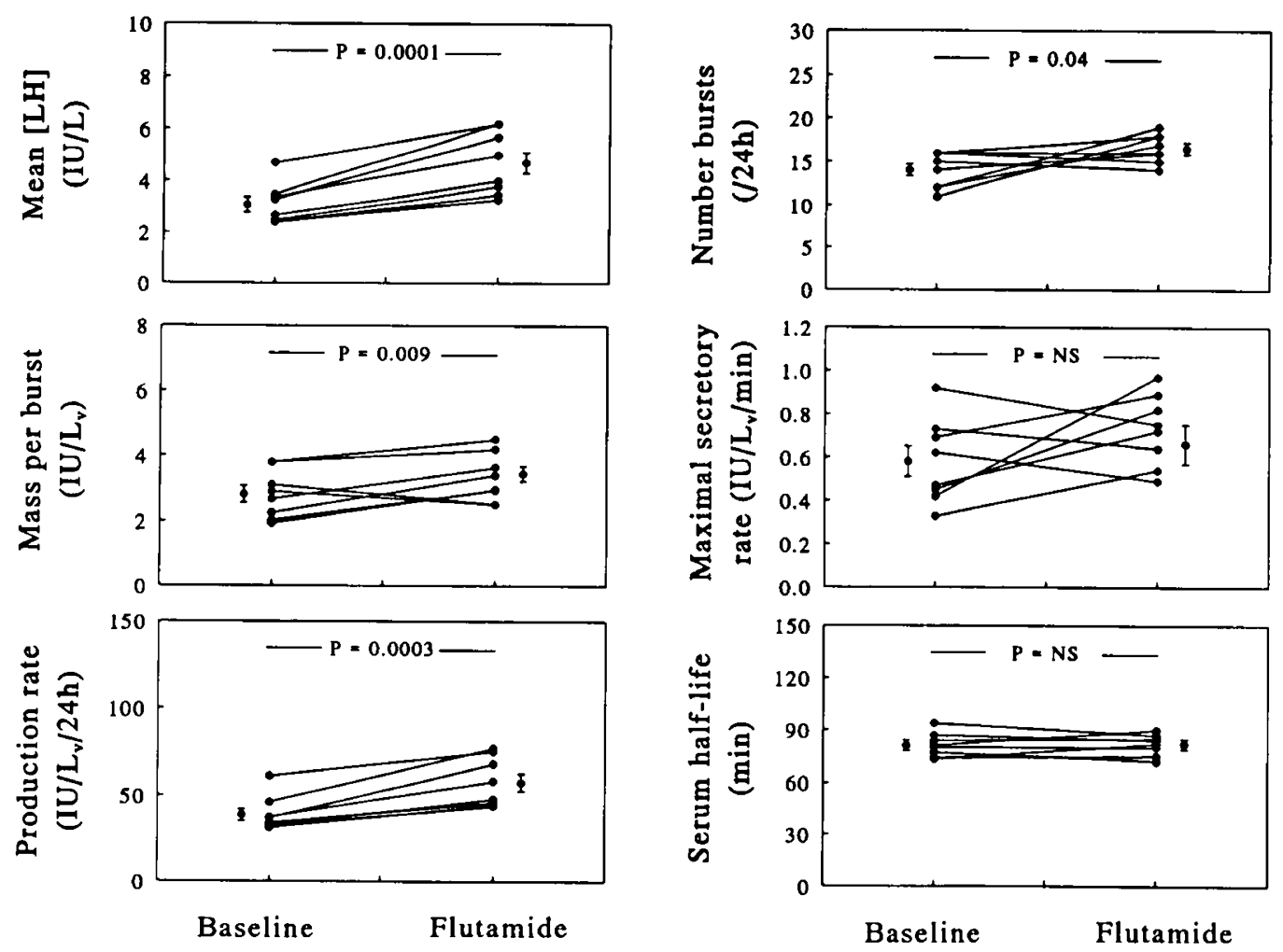

Fig. 2. Quantitative results of LH secretory and elimination parameters, as estimated by deconvolution analysis in all eight subjects. Tie bars connect the results of both experimental conditions for individual subjects. Solid circles and error bars represent the mean \pm SEM of the adjoining set of data. See text for definition of deconvolution analysis-derived parameters.

Table 2. GnRH-stimulated $L H$ secretion during androgenreceptor blockade*

\begin{tabular}{lccc}
\hline & Baseline & Flutamide & $p$ \\
\hline Peak serum LH concentration (IU/L) & $19 \pm 3$ & $17 \pm 2$ & NS \\
Incremental serum LH concentration & $16 \pm 2$ & $12 \pm 2$ & NS
\end{tabular}

$(\mathrm{IU} / \mathrm{L})$ increase $(\Delta)$

* Peak LH represents the maximal serum LH concentration achieved after GnRH stimulation and $\triangle \mathrm{LH}$ represents the arithmetic difference between the peak $\mathrm{LH}$ concentration and the mean serum level of $\mathrm{LH}$ before $\mathrm{GnRH}$ administration. Data are mean $\pm \operatorname{SEM}(n=8$ subjects $)$.

GnRH-stimulation testing were utilized in a cohort of late pubertal male subjects administered the potent, nonsteroidal antiandrogen, flutamide (24).

The pattern of circulating gonadotropin concentrations in the adolescent male is pulsatile $(2,3,25)$. Presumably, these momentary surges in serum gonadotropin levels result from episodic stimulation of the pituitary by hypothalamic GnRH. Studies in animals (26-28) have suggested a coordinate relationship between the hypothalamic neuronal "pulse-generator," hypophyseal portal GnRH concentrations and pulsations in plasma LH levels. Consequently, indirect inferences about GnRH action may be based on patterns of peripheral LH concentrations in the human.

We observed discrete episodes of gonadotropin secretion in the late pubertal male. LH release occurred in random bursts of finite duration without demonstrable tonic hormone secretion. The frequency of such LH secretory events in our subjects corresponded to approximately one event every $100 \mathrm{~min}$, which is in good agreement with the frequency of serum LH pulsations observed by other investigators $(2,3,25)$. Hence, the fluctuating levels of circulating gonadotropins can be ascribed to burst-like secretion of pituitary $\mathrm{LH}$, which is then acted upon simultaneously by metabolic clearance. By inference, dynamic variations in $\mathrm{GnRH}$ release and action underlie the pulsatile pattern of $\mathrm{LH}$ release in the pubertal male.

When androgen feedback action is attenuated by therapeutically effective serum concentrations of 2-hydroxyflutamide as measured here, heightened LH production occurs in the pubertalaged male. The mechanism of increased daily $\mathrm{LH}$ production was clarified further by deconvolution analysis, which showed that contributing to greater LH secretion are increases in LH secretory burst frequency and the mass of hormone released per secretory episode. No demonstrable change in the calculated elimination rate of LH occurs during androgen-receptor antagonism. The derived estimate of serum LH half-life in our subjects agrees closely with the range of 74 to $111 \mathrm{~min}$ observed for the slow component disappearance of exogenously administered purified human pituitary LH (immunoassayable and bioassayable gonadotropin) in the adult male (29). The net result of antiandrogen administration is higher $24-\mathrm{h}$ mean serum $\mathrm{LH}$ concentrations. These increased levels of serum LH assessed in an fluoroimmunoassay were presumably bioactive, because serum concentrations of total testosterone and estradiol and free testosterone all increased significantly. This pattern is consistent with that observed in inborn errors of the androgen receptor (e.g. testicular feminization), in which increased LH secretion occurs despite high circulating androgen and estrogen concentrations $(12,30)$. Of interest, FSH concentrations did not increase significantly, which may reflect suppressive effects of the mild hyperestrogenemia on FSH secretion and/or increased negative feedback effects of nonsteroidal products of the testes, such as inhibin (not measured here). Thus, assuming that flutamide does not cause any changes in gonadotropin or steroid hormone distribution volumes or half-lives of elimination, our findings indicate that late pubertal males can amplify the daily production of bioactive LH via specific enhancement of LH secretory burst frequency and mass of hormone released per secretory event, when the negative feedback actions of endogenous androgens on the androgen receptor are relieved. 
Flutamide administration had no demonstrable effect on GnRH-stimulated $\mathrm{LH}$ release suggesting that androgen does not influence gonadotropin secretion at the pituitary level. This finding supports the conclusion of Kletter and colleagues $(8,31)$ that, in the pubertal male, the principal site of androgen negativefeedback on the reproductive axis is the hypothalamus. Because LH secretory burst mass increased during flutamide treatment, we can suggest that the amount of endogenous GnRH released per burst also increased. We cannot discount the possibility, however, that provocation with submaximal doses of GnRH would reveal more subtle androgen-induced changes in gonadotrope secretory responses to the secretagogue. Because increased concentrations of testosterone and estrogen occurred as a result of heightened $\mathrm{LH}$ release during antiandrogen administration, we recognize the possibility that unopposed estrogen action might have diminished somewhat the pituitary response to GnRH stimulation $(13,32)$. However, antiestrogen administration in young men does not augment the stimulatory effects of a submaximal dose of exogenous GnRH (15) on bioactive $\mathrm{LH}$ secretion. Accordingly, our demonstration of increased LH secretory burst frequency and mass with no changes in pituitary responsiveness to exogenous $\mathrm{GnRH}$ is consistent with heightened GnRH burst frequency and GnRH burst amplitude.

In summary, androgen negative-feedback action on the CNShypothalamic-pituitary axis is exerted primarily at the hypothalamus in the late pubertal-aged male. By attenuating androgen action in late pubertal boys, we can infer that physiological amounts of androgen dampen the activity of the GnRH pulsegenerator and the associated GnRH pulse stimulus to the pituitary, thereby providing effective modulatory control of pulsatile gonadotropin secretion in the young adult.

Acknowledgments. The authors are indebted to Sandra Jackson and the nursing staff at The General Clinical Research Center for their expert care of research subjects and to Ginger Bauler, Catherine Kern, C. Lynn Bentley, and Diana Ellerman for technical assistance. The authors acknowledge the clerical assistance of Susan Lorek Fitzgerald and the generous assistance of Schering Corporation with the 2-hydroxyflutamide determinations.

\section{REFERENCES}

1. Boyar RM, Rosenfeld RS, Kapen S, Finkelstein JW, Roffwarg HP, Weitzman ED, Hellman L 1974 Human puberty: simultaneous augmented secretion of luteinizing hormone and testosterone during sleep. J Clin Invest 54: 609-618

2. Oerter KE, Uriarte MM, Rose SR, Barnes KM, Cutler Jr GB 1990 Gonadotropin secretory dynamics during puberty in normal girls and boys. $\mathrm{J}$ Clin Endocrinol Metab 71:1251-1258

3. Wu FCW, Butler GE, Kelnar CJH, Sellar RE 1990 Patterns of pulsatile luteinizing hormone secretion before and during the onset of puberty in boys: a study using an immunoradiometric assay. J Clin Endocrinol Metab 70:629-637

4. Urban RJ, Evans WS, Rogol AD, Kaiser DL, Johnson ML, Veldhuis JD 1988 Contemporary aspects of discrete peak-detection algorithms. I. The paradigm of the luteinizing hormone pulse signal in men. Endocr Rev 9:3-37

5. Sheckter CB, Matsumoto AM, Bremner WJ 1989 Testosterone administration inhibits gonadotropin secretion by an effect directly on the human pituitary. J Clin Endocrinol Metab 68:397-401

6. Kelch RP, Hopwood NJ, Sauder S, Marshall JC 1985 Evidence for decreased secretion of gonadotropin-releasing hormone in pubertal boys during shortterm testosterone treatment. Pediatr Res 19:112-117

7. Foster CM, Hassing JM, Mendes TM, Hales PM, Padmanabhan V, Hopwood NJ, Beitins IZ, Marshall JC, Kelch RP 1989 Testosterone infusion reduces nocturnal luteinizing hormone pulse frequency in pubertal boys. J Clin Endocrinol Metab 69:1213-1220
8. Kletter GB, Foster CM, Brown MB, Padmanabhan V, Beitins IZ, Marshall JC, Kelch RP 1991 Naloxone does not reverse the suppressive effects of testosterone infusion on luteinizing hormone secretion in pubertal boys. J Clin Endocrinol Metab 73:1241-1247

9. Finkelstein JS, Randall W, Whitcomb RW, St. L. O'Dea L. Longcope C. Schoenfeld DA, Crowley Jr WF 1991 Sex steroid control of gonadotropin secretion in the human male. I. Effects of testosterone administration in normal and gonadotropin-releasing hormone-deficient men. J Clin Endocrinol Metab 73:609-620

10. Urban RJ, Davis MR, Rogol AD, Johnson ML, Veldhuis JD 1988 Acute androgen receptor blockade increases luteinizing hormone secretory activity in men. J Clin Endocrinol Metab 67:1149-1155

11. Veldhuis JD, Urban RJ, Dufau ML 1992 Evidence that androgen negativefeedback regulates hypothalamic gonadotropin-releasing hormone impulse strength and the burst-like secretion of biologically active luteinizing hormone in men. J Clin Endocrinol Metab 74:1227-1235

12. LaCroix A, McKenna TJ, Rabinowitz D 1979 Sex steroid modulation of gonadotropins in normal men and in androgen insensitivity syydrome. J Clin Endocrinol Metab 48:235-240

13. Barbarino A, De Marinis L, Mancini A 1983 Estradiol modulation of basal and gonadotropin-releasing hormone-induced gonadotropin release in intact and castrated men. Neuroendocrinology 36:105-111

14. Winters SJ, Troen $P 1985$ Evidence for a role of endogenous estrogen in the hypothalamic control of gonadotropin secretion in men. J Clin Endocrinol Metab 61:842-845

15. Veldhuis JD, Dufau M 1987 Estradiol modulates the pulsatile secretion of biologically active luteinizing hormone in man. J Clin Invest 80:631-638

16. Finkelstein JS, St. L. O'Dea L, Whitcomb RW, Crowley Jr WF 1991 Sex steroid control of gonadotropin secretion in the human male. II. Effects of estradiol administration in normal and gonadotropin-releasing hormonedeficient men. J Clin Endocrinol Metab 73:621-628

17. Veldhuis JD, Carlson ML, Johnson ML 1987 The pituitary gland secretes in bursts: appraising the nature of glandular secretory impulses by simultaneous multiple-parameter deconvolution of plasma hormone concentrations. Proc Natl Acad Sci USA 84:7686-7690

18. Veldhuis JD, Johnson ML 1992 Deconvolution analysis of hormone data. Methods Enzymol 210:539-575

19. Marshall WA, Tanner JM 1970 Variation in the pattern of pubertal changes in boys. Arch Dis Child 45:13-23

20. Hammer LD, Kraemer HC, Wilson DM, Ritter PL, Dornbusch SM 1991 Standardized percentile curves of body-mass index for children and adolescents. Am J Dis Child 145:259-263

21. Veldhuis JD, Iranmanesh A, Lizzaralde G, Johnson ML 1989 Amplitude modulation of a burst-like mode of cortisol secretion subserves the circadian glucocorticoid rhythm in man. Am J Physiol 257:E6-E14

22. Veldhuis JD, Faria A Vance ML, Evans WS, Thorner MO, Johnson ML 1988 Contemporary tools for the analysis of episodic growth hormone secretion and clearance in vivo. Acta Paediatr Scand 347:63-82

23. Quercia RA 1989 Focus of flutamide: a nonsteroidal antiandrogenic chemotherapeutic agent. Hosp Formul 24:421-428

24. Neri R, Florance K, Koziol P, Van Cleave S 1972 A biological profile of a nonsteroidal antiandrogen, $\mathrm{SCH} 13521$ (4'-Nitro-3'-Trifluoromethylisobutyranilide). Endocrinology 91:427-437

25. Dunkel L, Alfthan H, Stenman U-H, Tapanainen P, Perheentupa J 1990 Pulsatile secretion of LH and FSH in prepubertal and early pubertal boys revealed by ultrasensitive time-resolved immunofluorometric assays. Pediatr Res 27:215-219

26. Clarke IJ, Cummins JT 1982 The temporal relationship between gonadotropin releasing hormone (GnRH) and luteinizing hormone (LH) secretion in ovariectomized ewes. Endocrinology 111:1737-1739

27. Levine JE, Ramirez VD 1982 Luteinizing hormone-releasing hormone release during the rat estrous cycle and after ovariectomy, as estimated with pushpull cannulae. Endocrinology 111:1439-1448

28. Wilson RC, Kesner JS, Kaufman JM, Uemura T, Akema T, Knobil E 1984 Central electrophysiologic correlates of luteinizing hormone secretion in the rhesus monkey. Neuroendocrinology 39:256-260

29. Veldhuis JD, Fraioli F, Rogol AD, Dufau M 1986 Metabolic clearance of biologically active luteinizing hormone in man. J Clin Invest 77:1122-1128

30. Veldhuis JD 1991 The hypothalamic-pituitary-testicular axis. In: Yen SSC, Jaffe RB (eds) Reproductive Endocrinology, Third Edition. WB Saunders, Philadelphia, pp 409-459

31. Kletter GB, Foster CM, Beitins IZ, Marshall JC, Kelch RP 1992 Acute effects of testosterone infusion and naloxone on luteinizing hormone secretion in normal men. J Clin Endocrinol Metab 75:1215-1219

32. Veldhuis JD, Sowers JR, Rogol AD, Dufau ML 1985 Pathophysiology of male hypogonadism with endogenous hyperestrogenism: evidence for dual defects in the gonadal axis. N Engl J Med 312:1371-1375 